Note

\title{
Myricanol and myricanone biosynthesis in Myrica rubra: incorporation of two molecules of 4-coumaric acid
}

Shingo Kawai • Kyousuke Nakata, • Masako Ohashi • Tomoaki Nishida

Shingo Kawai $(\bowtie) \cdot$ Kyousuke Nakata • Masako Ohashi • Tomoaki Nishida

Laboratory of Forest Microbiology and Biochemistry,

Department of Environment and Forest Resources Science,

Faculty of Agriculture, Shizuoka University

Ohya, Suruga-ku, Shizuoka 422-8529, JAPAN

Tel. +81-54-238-4851; Fax +81-54-238-4851

e-mail: skawai@agr.shizuoka.ac.jp

Key words Cyclic diarylheptanoids • Myricanol Biosynthesis • 4-Coumaric acid •

${ }^{13} \mathrm{C}-\mathrm{NMR} \cdot$ Myrica rubra

Part of this report was presented at the 56th Annual Meeting of the Japan Wood Research Society, Akita, August 2006. 


\begin{abstract}
Feeding experiments of Myrica rubra young shoot with 4-[8,9- $\left.{ }^{13} \mathrm{C}_{2}\right]$ coumaric acid revealed that the cyclic diarylheptanoids, myricanol and myricanone, were derived from two molecules of 4-coumaric acid by mass spectrometric analyses.

${ }^{13} \mathrm{C}-\mathrm{NMR}$ of myricanol isolated after administration of $4-\left[8,9-{ }^{13} \mathrm{C}_{2}\right]$ coumaric acid demonstrated that C-8 and C-9 atoms of 4-coumaric acid are incorporated into C-8, C-9, C-11 and C-12 of corresponding myricanol.
\end{abstract}




\section{Introduction}

Diarylheptanoids comprise a class of natural products based on 1,7-diphenylhentane. Many kinds of diarylheptanoids have been isolated from Myricaceae, Betulaceae, Zingiberaceae, and Aceraceae plants. ${ }^{1}$ The bark of Myrica rubra Sieb. et Zucc. has been used as an astringent, antidote and antidiarrheal in Japanese folk medicine and has also been used externally for burn and skin diseases in Chinese traditional medicine. In M. rubra, the cyclic diarylheptanoids, myricanol (1) and myricanone (2), are one of the major components. ${ }^{2,3}$ Recently, it has been reported that they have antitumor-promoting effects ${ }^{4}$ and anti-androgen activities. ${ }^{5}$

The biosynthesis of diarylheptanoids, especially phenylphenalenone derivatives, ${ }^{6-9}$ has been investigated and reported that two molecules of phenylpropanoids and one malonyl-CoA were concerned with the formation of phenylphenarenone skeleton. However, there is no evidence about the biosynthetic pathways for cyclic diarylheptanoids.

In this paper, we described in vivo feeding experiments using the

${ }^{13} \mathrm{C}$-labeled 4-coumaric acid (3). Biosyntheitc MS and ${ }^{13} \mathrm{C}$-NMR studies indicated the involvement of two molecules of 4-coumaric acid (3) for the formation of acid to cyclic diarylheptanoids, myricanol (1) and myricanone (2), in M. rubra.

\section{Materials and Methods}

Analytical and preparative TLC were performed on silica gel (Merck Kieselgel $60 \mathrm{~F}_{254}$ ). Silica gel column chromatography employed Kieselgel 60 (70 - 230 mesh, Merck). ${ }^{1} \mathrm{H}$ and ${ }^{13} \mathrm{C}$-NMR spectra were taken with JEOL JMM EX-270 and JEOL LAMBDA 500 FT-NMR spectrometers using tetramethylsilane as an internal standard. EI-MS analyses were performed with a 
Shimadzu GCMS-QP 5050 gas chromatograph mass spectrometer (70 eV).

GC-MS analyses were carried out on a capillary column (TC-1; 30 m x 0.25 mm i.d.; film, $1 \mu \mathrm{m}$; GL Sciences) at a rate of $5^{\circ} \mathrm{C} \min ^{-1}$ from 150 to $280{ }^{\circ} \mathrm{C}$.

Extraction and isolation of authentic myricanol (1) and myricanone (2).

Branches of Myrica rubura Sieb. et Zucc. grown on the campus of Shizuoka University were harvested on June 2004. The xylem and bark were air dried and powdered. The powder (368 g) was extracted with hot $\mathrm{MeOH}$ for $23 \mathrm{~h}$. The $\mathrm{MeOH}$ extracts were dissolved in EtOAc, and soluble part for EtOAc was partitioned with saturated $\mathrm{NaHCO}_{3}$ and $1 \mathrm{~N} \mathrm{NaOH}$, successively. The $\mathrm{NaOH}$ layer was acidified with $6 \mathrm{~N} \mathrm{HCl}$ to $\mathrm{pH} 2$ and it was extracted with EtOAc. The EtOAc extracts were chromatographed on a column of silica gel (eluent: ethyl acetate/n-hexane, 1/2). The fractions containing myricanol (1) and myricanone (2) were combined, respectively. Myricanol (1) (36.4 mg) was further purified by TLC (solvent: $\mathrm{MeOH} / \mathrm{CHCl}_{3}, 2 / 98$ ) separation and analyzed by NMR and MS. Myricanone (2) was only identified by GC- and direct inlet (DI)-MS analysis. Myricanol (1)

${ }^{1} \mathrm{H}-\mathrm{NMR}\left(\mathrm{CDCl}_{3}, 270 \mathrm{~Hz}\right){ }^{10} \delta$ (ppm): 1.50-1.60 (2H, m, 9-H, 10-H), 1.85-2.00 (3H, m, 8- $\left.\mathrm{H}_{2}, 10-\mathrm{H}\right)$, 1.65-1.75 (2H, m, 9-H, 12-H), 2.25-2.37 (1H, m, 12-H), 2.45-2.60 (1H, m, 7-H), 2.75-2.89 (1H, m, 7-H), 2.89-2.95 (2H, m, 13- $\left.\mathrm{H}_{2}\right), 3.88$ (3H, s, $\left.-\mathrm{OCH}_{3}\right), 3.99\left(3 \mathrm{H}, \mathrm{s},-\mathrm{OCH}_{3}\right), 4.08(1 \mathrm{H}, \mathrm{bt}, J=9.9 \mathrm{~Hz}, 11-\mathrm{H}), 5.94(1 \mathrm{H}, \mathrm{bs}$, 5-OH), 6.88 (1H, s, 19-H), 6.90 (1H,d, $J=8.2 \mathrm{~Hz}, 16-\mathrm{H}), 7.08$ (1H, dd, $J=8.2$, 2.3Hz, 15-H), 7.17 (1H, d, J=2.3Hz, 18-H), 7.68 (1H, bs, 17-OH).

${ }^{13} \mathrm{C}-\mathrm{NMR}\left(\mathrm{CDCl}_{3}, 125 \mathrm{~Hz}\right) \delta$ (ppm): 22.9 (9-C), 25.4 (7-C), 25.7 (8-C), 26.9 (13-C), 34.7 (12-C), 39.4 (10-C), 61.4 (-OCH 3 x 2), 68.6 (11-C), 116.8 (16-C), 
122.6 (6-C), 123.4 (2-C), 124.7 (1-C), 129.4 (19-C), 130.0 (15-C), 130.7 (14-C),

133.1 (18C), 138.7 (4-C), 145.9 (3-C), 147.7 (5-C), 151.3 (17-C).

MS (DI) m/z (\%): 136 (20), 257 (27), 271 (22), 297 (20), 358 ( $\left.\mathrm{M}^{+}, 100\right), 359$ (23);

(TMS ether, GC) m/z (\%):73 (100), 145 (13), 427 (6), 453 (9), $574\left(\mathrm{M}^{+}, 53\right)$.

Myricanone (2)

MS (DI) m/z (\%): 128 (14), 143 (20), 271 (21), 285 (18), 356 (M+, 100), 357 (24);

(TMS ether, GC) m/z (\%): 73 (100), 75 (22), 87 (24), 207 (32), $500\left(\mathrm{M}^{+}, 45\right)$.

Syntheses of labeled precursor

Ethyl 4-[8,9- $\left.{ }^{13} C_{2}\right]$ acetoxycinnamate (4)

Ethyl 4-[8,9- $\left.{ }^{13} \mathrm{C}_{2}\right]$ acetoxycinnamate (4) was synthesized by Wittig-Horner reaction from 4-acetoxybenzaldehyde and ${ }^{13} \mathrm{C}$-labeled triethyl phosphonoacetate (TEPA) by the modified method of Newman et al. ${ }^{11}$

4-Hydroxybenzaldehyde was acetylated with acetic anhydride and pyridine (1/1) to give 4-acetoxybenzaldehyde. To a solution of 4-acetoxybenzaldehyde (271 mg, $1.65 \mathrm{mmol}$ ) and [1,2- $\left.{ }^{13} \mathrm{C}_{2}\right] \mathrm{TEPA}$ (250 mg, 1.1 mmol, Aldrich, 99 atom $\left.\%{ }^{13} \mathrm{C}_{2}\right)$ in toluene (2 ml), powdered $\mathrm{KOH}(85 \%, 109 \mathrm{mg}$, $1.65 \mathrm{mmol}$ ) and 18-Crown-6 (349 mg, $1.32 \mathrm{mmol}$ ) were added under nitrogen atmosphere. ${ }^{12}$ The resulting solution was stirred at ambient temperature for 30 min. The reaction mixture was partitioned between ethyl acetate and water. The organic layer was washed with water (twice) and saturated brine (twice), successively. It was dried over anhydrous $\mathrm{Na}_{2} \mathrm{SO}_{4}$ and evaporated under reduced pressure. The residue (394 mg) was purified by column chromatography (eluent: ethyl acetate/n-hexane, $1 / 4)$ to give ethyl $4-\left[8,9-{ }^{13} C_{2}\right]$ acetoxycinnamate (4) (161 mg, $62 \%$ from TEPA). 
${ }^{13} \mathrm{C}-\mathrm{NMR}\left(\mathrm{CDCl}_{3}, 67.5 \mathrm{~Hz}\right) \delta(\mathrm{ppm}):$

${ }^{13}$ C-enriched-4: 118.4 (d, J=75.7 Hz, 8-C), 166.8 (d, $J=75.6$ Hz, 9-C).

Non-labeled authentic-4: $14.3\left(-\mathrm{OCH}_{2} \underline{\mathrm{CH}_{3}}\right), 21.1\left(-\mathrm{OCOC}_{3}\right), 60.5\left(-\mathrm{OCH}_{2} \mathrm{CH}_{3}\right)$, 118.4 (8-C), 122.1 (3,5-C $), 129.1$ (2,6-C 2 ), 132.2 (1-C), 143.4 (7-C), 152.0 (4-C), 166.8 (9-C), $169.1\left(-\mathrm{OCOCH}_{3}\right)$.

4- $\left[8,9-{ }^{13} C_{2}\right]$ coumaric acid (3)

To a solution of ethyl $4-\left[8,9-{ }^{13} \mathrm{C}_{2}\right]$ acetoxycinnamate (4) (161 mg, 0.68 mmol) in 80\% ethanol (2 ml), powdered $\mathrm{KOH}$ (85 \%, $360 \mathrm{mg}, 5.4 \mathrm{mmol}$ ) was added under nitrogen atmosphere. The resulting solution was stirred at ambient temperature for $26 \mathrm{~h}$. The reaction mixture was partitioned between ethyl acetate and water. The organic layer was washed with saturated brine (twice), dried over anhydrous $\mathrm{Na}_{2} \mathrm{SO}_{4}$ and evaporated under reduced pressure. The residue was purified by TLC (solvent: $\mathrm{MeOH}-\mathrm{CHCl}_{3}, 5 / 95$ ) to give $4-\left[8,9-{ }^{13} \mathrm{C}_{2}\right]$ coumaric acid (3) (95.5 mg, $84 \%)$.

DI-MS $m / z(\%)$ :

${ }^{13}$ C-enriched-3: 65 (12), 92 (20), 119 (22), 120 (26), 149 (39), 163 (0.2), 164 (1.6), 165 (44), 166 (100), 167 (9).

None-labeled authentic-3: 65 (19), 91 (22), 118 (22), 119 (26), 147 (39), 163 (41), $164\left(\mathrm{M}^{+}, 100\right), 165$ (11), 166 (1.6), 167 (0.2).

${ }^{13} \mathrm{C}-\mathrm{NMR}\left(\mathrm{CD}_{3} \mathrm{OD}, 67.5 \mathrm{~Hz}\right) \delta(\mathrm{ppm})$ :

${ }^{13} \mathrm{C}$-enriched-3: 115.7 (d, $\left.J=73.8 \mathrm{~Hz}, 8-\mathrm{C}\right), 171.0$ (d, J=73.2 Hz, 9-C).

Non-labeled authentic-3: 115.6 (8-C), 116.8 (3,5-C $)$, 127.3. (1-C), 131.0 (2,6-C2), 146.6 (7-C), 161.2 (4-C), 171.0 (9-C).

Feeding experiment 
4-[8, 9- $\left.{ }^{13} \mathrm{C}_{2}\right]$ coumaric acid (3) (25 mM in $0.1 \% \mathrm{NaOH}, 1 \mathrm{ml}$ each) was administrated to excised M. rubura young shoots (harvested on October and November, 2005, shoot size: 20-30 cm), which were allowed to metabolize for 2 weeks at room temperature under continuous light. After incubation, the leaves were removed from the resulting shoots, and stems were frozen, powdered with a pestle and mortar, and extracted with hot $\mathrm{MeOH}$ for $12 \mathrm{hr}$. The extracts were partitioned between EtOAc and water. The organic layer was washed with brine, dried over anhydrous $\mathrm{Na}_{2} \mathrm{SO}_{4}$, and evaporated under reduced pressure. The myricanol (1) and myricanone (2) fractions were roughly separated from the extracts by TLC (solvent: ethyl acetate/n-hexane, $1 / 2$ ), respectively. The both fractions were trimethylsilylated [TMSI-H (hexamethyldisilazane and trimethylchlorosilane in pyridine $(2: 1: 10, \mathrm{v} / \mathrm{v}))(\mathrm{GL}$ Sciences)] and analyzed by GC-MS. The myricanol (1) and myricanone (2) fractions confirmed the incorporation of 4-[8,9- $\left.{ }^{13} \mathrm{C}_{2}\right]$ coumaric acids (3) by GC-MS analyses were combined, respectively, and further purified by TLC (solvent: $\mathrm{MeOH}-\mathrm{CHCl}_{3}$, 2/95). The purified myricanol (1) ( $3 \mathrm{mg})$ and myricanone (2) $(<1 \mathrm{mg})$ were analyzed by selected ion monitoring (SIM) of DI-MS, respectively. ${ }^{13} \mathrm{C}-\mathrm{NMR}$ analysis of the myricanol (1) was also performed.

\section{Results and Discussion}

4-[8,9- $\left.{ }^{13} \mathrm{C}_{2}\right]$ Coumaric acid (3) was administrated to excised M. rubra young shoots and it was allowed to metabolize for 2 weeks. The shoots was grounded and extracted with hot $\mathrm{MeOH}$. The myricanol (1) and myricanone (2) fractions, obtained by TLC separation, were analyzed by GC-MS, respectively. Comparison with the mass spectra of unlabeled authentic compounds (Fig. 1), the spectra of myricanol (1-TMS ether) and myricanone (2-TMS ether) obtained 
following administration of $4-\left[8,9-{ }^{13} \mathrm{C}_{2}\right]$ coumaric acid (3) clearly demonstrated that the molecular ions of unlabeled myricanol (1) at $\mathrm{m} / \mathrm{z} 574$ and myricanone (2) at $m / z 500$ are accompanied by extra ions at $m / z 578$, and 504 , respectively, indicating the formations of $\left[{ }^{13} \mathrm{C}_{4}\right]$-myricanol and $\left[{ }^{13} \mathrm{C}_{4}\right]$-myricanone. The myricanol (1) and myricanone (2) fractions were further purified by TLC to confirm the incorporation rate of ${ }^{13} \mathrm{C}$ carbon into myricanol (1) and myricanone (2) using DI-MS with SIM mode. As shown in Table 1, the results indicated that ca. $6 \%$ of myricanol (1) and ca. $9.5 \%$ of myricanone (2) were biosynthesized from two molecules of $4-\left[8,9-{ }^{13} \mathrm{C}_{2}\right]$ coumaric acid (3), respectively.

Furthermore, to determine the ${ }^{13} \mathrm{C}$-enriched position in the side chains, ${ }^{13}$ C-NMR analysis of myricanol (1) was conducted (Fig. 2). The NMR spectra of the isolated myricanol (1) displayed an enhancement of ${ }^{13} \mathrm{C}$ resonances at four positions. Due to ${ }^{13} \mathrm{C}-{ }^{13} \mathrm{C}$ coupling, the resonances of $\mathrm{C}-8$ ( $\delta$ 25.7), C-9 ( $\delta$ 22.9), C-11 ( $\delta$ 68.6), and C-12 ( $\delta$ 34.7) appear as pseudo triplet, indicating the occurrence of naturally-occurring isotopomers (singlet, central resonances of the pseudo triplets) and relatively high amounts of isotopomers containing two labeled carbons in these positions (doublets, C-8; $J=35.2 \mathrm{~Hz}, \mathrm{C}-9 ; J=34.1 \mathrm{~Hz}$, C-11; $J=39.3 \mathrm{~Hz}, \mathrm{C}-12 ; J=39.3 \mathrm{~Hz}$ ). It is clear that the doublets signals of this compound derived from $4-\left[8,9-{ }^{13} \mathrm{C}_{2}\right]$ coumaric acid (3), and the relative intensities of the enhanced doublet signals based on the singlet signals were 5.32 for C-8, 5.34 for C-9, 4.46 for C-11 and 4.56 for C-12, respectively.

The possible biosynthetic pathway from 4-coumaric acid to myricanol (1) and myricanone (2) was shown in Fig. 3. The present investigations clearly demonstrated that two molecules of 4-coumaric acid (3) were concerned with the formation of diarylheptanoids skeleton in M. rubra. 
In the biosynthesis of diarylheptanoids, the involvement with chalcone synthase related type III plant polyketide synthase (PKS III) is presumed. ${ }^{13}$ Very recently, Brand et al. ${ }^{14}$ has reported that a new PKS III gene has been cloned from Wachendorfia thyrsiflora, and the enzyme catalyzed the formation of a diketide, which is considered as a biosynthetic intermediate of phenylphenalenone derivatives. Furthermore, Ramirez-Ahumada et al. ${ }^{15}$ has detected the acitivity of curucuminoid synthase in turmeric, which required both 4-hydroxycinnamyl-CoA esters and malonyl-CoA for curcuminoid biosynthesis. Therefore, similar enzymes might be involved in the biosynthesis of myricanol derivatives in $M$. rubra. However, there are no carbon-carbon double bond in the heptane side chain of myricanol derivatives, (1) and (2), and it is unclear whether the saturated structure in myricanols was originated from dihydrocinnamic acid precursor(s) or from a cinnamic acid precursor followed by hydrogenation after condensation with a second cinnamate unit. Further feeding experiments with ${ }^{13} \mathrm{C}$-labeled 4-hydroxyphenylpropanic acid are in progress for this question. The origin of the methoxyl groups in myricanol (1) and myricanone (2) also remains to be resolved. We are presently attempting to determine whether ${ }^{13} \mathrm{C}$-labeled ferulic acid is incorporated into myricanol derivatives (1) and (2). 
Acknowledgement The author wish to thank Akihito Yagi, Technical Support Division, Faculty of Agriculture, Shizuoka University, for assistance with NMR analyses. 


\section{References}

1. Inoue T (1993) Constituents of Acer nikoense and Myrica rubra. On diarylheptanoids (in Japanese). Yakugaku Zasshi 113:181-197.

2. Begley MJ, Campbell RVM, Crombie L, Tuck B, Whiting DA (1971) Constitution and absolute configuration of meta,meta-bridged, strained biphenyls from Myrica nagi; X-ray analysis of 16-bromomyricanol. J Chem Soc (C) 3634-3642.

3. Inoue T, Arai Y, Nagai, M (1984) Diarylheptanoids in the bark of Myrica rubra Sieb. et Zucc. (in Japanese). Yakugaku Zasshi 104:37-41.

4. Ishida J, Kozuka M, Wang HK, Konoshima T, Tokuda H, Okuda M, Mou XY, Nishino H, Sakurai N, Lee KH, Nagai M (2000) Antitumor-promoting effects of cyclic diarylheptanoids on Epstein-Barr virus activation and two-stage mouse skin carcinogenesis. Cancer Lett 159:135-140.

5. Matsuda H, Yamazaki M, Matsuo K, Asanuma Y, Kubo M (2001) Anti-androgenic activity of Myricae Cortex - Isolation for active constituents from bark of Myrica rubra. Biol Pharm Bull 24:259-263.

6. Hölscher D, Schneider B (1995) A diarylheptanoid intermediate in the biosynthesis of phenylphenalenones in Anigozanthos preissi. J Chem Soc Chem Commun 525-526.

7. Hölscher D, Schneider B (2005) The biosynthesis of 8-phenylphenalenones from Eichhornia crassipes involves a putative aryl migration step. Phytochem 66:59-64.

8. Schneider B, Gershenzon J, Graser G, Schmitt B, Hölscher D (2003) One-dimensional ${ }^{13} \mathrm{C}$ NMR and HPLC- ${ }^{1} \mathrm{H}$ NMR techniques for observing carbon-13 and deuterium labeling in biosynthetic studies. Phytochem Rev 2:31-43. 
9. Kamo T, Hirai N, Tsuda M, Fujioka D, Ohigashi H (2000) Changes in the content and biosynthesis of phytoalexins in banana fruit. Biosci Biotechnol Biochem 64:2089-2098.

10. Joshi BS, Pelletoer W (1996) Extensive 1D, 2D NMR spectra of some [7.0]metacyclophanes and X-ray analysis of ( \pm )-myricanol. J Nat Prod 59:759-764.

11. Newman J, Rej RN, Just, G, Lewis NG (1986) Synthesis of $\left(1,2-{ }^{13} \mathrm{C}\right),\left(1-{ }^{13} \mathrm{C}\right)$, and $\left(3{ }^{13} \mathrm{C}\right)$ coniferyl alcohol. Holzforschung 40:369-373.

12. Kawai S, Jensen KA, Bao W, Hammel KE (1995) New polymeric model substrates for study of microbial ligninolysis. Appl Environ Microbiol 61:3407-3414.

13. Schröder J (1997) A family of plant-specific polyketide synthase: facts and predictions. Trends Plant Sci 2:373-378.

14. Brand S, Hölscher D, Schierhorn A, Svatos A, Schröder J, Schneider B (2006) A type III polyketide synthase from Wachendorfia thyrsiflora and its role in diarylheptanoid and phenylphenalenone biosynthesis. Planta 224:413-428.

15. Ramirez-Ahumada M del C, Timmermann BN, Gang DR (2006) Biosynthesis of curcuminoids and gingerols in turmeric (Curcuma longa) and ginger (Zingiber officinale): Identification of curcuminod synthase and hydroxycinnammoyl-CoA thioesterases. Phytochem 67:2017-2029. 
Table 1. Mass spectral data of molecular-ion region of myricanol (1) and myricanol (2) isolated from M. rubra

\begin{tabular}{|c|c|c|c|c|c|}
\hline \multicolumn{3}{|c|}{ Myricanol (1) } & \multicolumn{3}{|c|}{ Myricanone (2) } \\
\hline \multirow[b]{2}{*}{$m / z$} & \multicolumn{2}{|r|}{ Relative intensity (\%) } & \multirow[b]{2}{*}{$m / z$} & \multicolumn{2}{|r|}{ Relative intensity (\%) } \\
\hline & Unlabeled & $\begin{array}{l}\text { Isolated after administration of } \\
44-\left[8,9-{ }^{13} \mathrm{C}_{2}\right] \text { coumaric acid (3) }\end{array}$ & & Unlabeled & $\begin{array}{l}\text { Isolated after administration of } \\
44-\left[8,9-{ }^{13} \mathrm{C}_{2}\right] \text { coumaric acid (3) }\end{array}$ \\
\hline 358 & 100 & 100 & 356 & 100 & 100 \\
\hline 359 & 23.1 & 24.4 & 357 & 23.8 & 24.9 \\
\hline 360 & 3.8 & 8.5 & 358 & 4.7 & 11.6 \\
\hline 361 & 0.5 & 2.9 & 359 & 0.9 & 3.9 \\
\hline 362 & 0.1 & 6.7 & 360 & 0.4 & 11.6 \\
\hline
\end{tabular}


Figure legends

Fig. 1. Mass spectra of myricanol TMS ethers (1-TMS, $\boldsymbol{A}, \boldsymbol{B})$ and myricanone TMS ethers (2-TMS, $\boldsymbol{C}, \boldsymbol{D}$ ). $\boldsymbol{A}, \boldsymbol{C}$ : unlabeled, $\boldsymbol{B}, \boldsymbol{D}$ : formed after 4-[8,9- $\left.{ }^{13} \mathrm{C}_{2}\right]$ coumaric acid (3) administration.

Fig. 2. $\quad{ }^{13}$ C-NMR spectra of myricanol (1). $\quad$ A: unlabeled, $\boldsymbol{B}$ : formed after $4-\left[8,9-{ }^{13} \mathrm{C}_{2}\right]$ coumaric acid (3) administration.

Fig. 3. Proposed biosynthetic pathways for myricanol (1) and myricanone (2) from 4-coumaric acid (3) in M. rubra. 

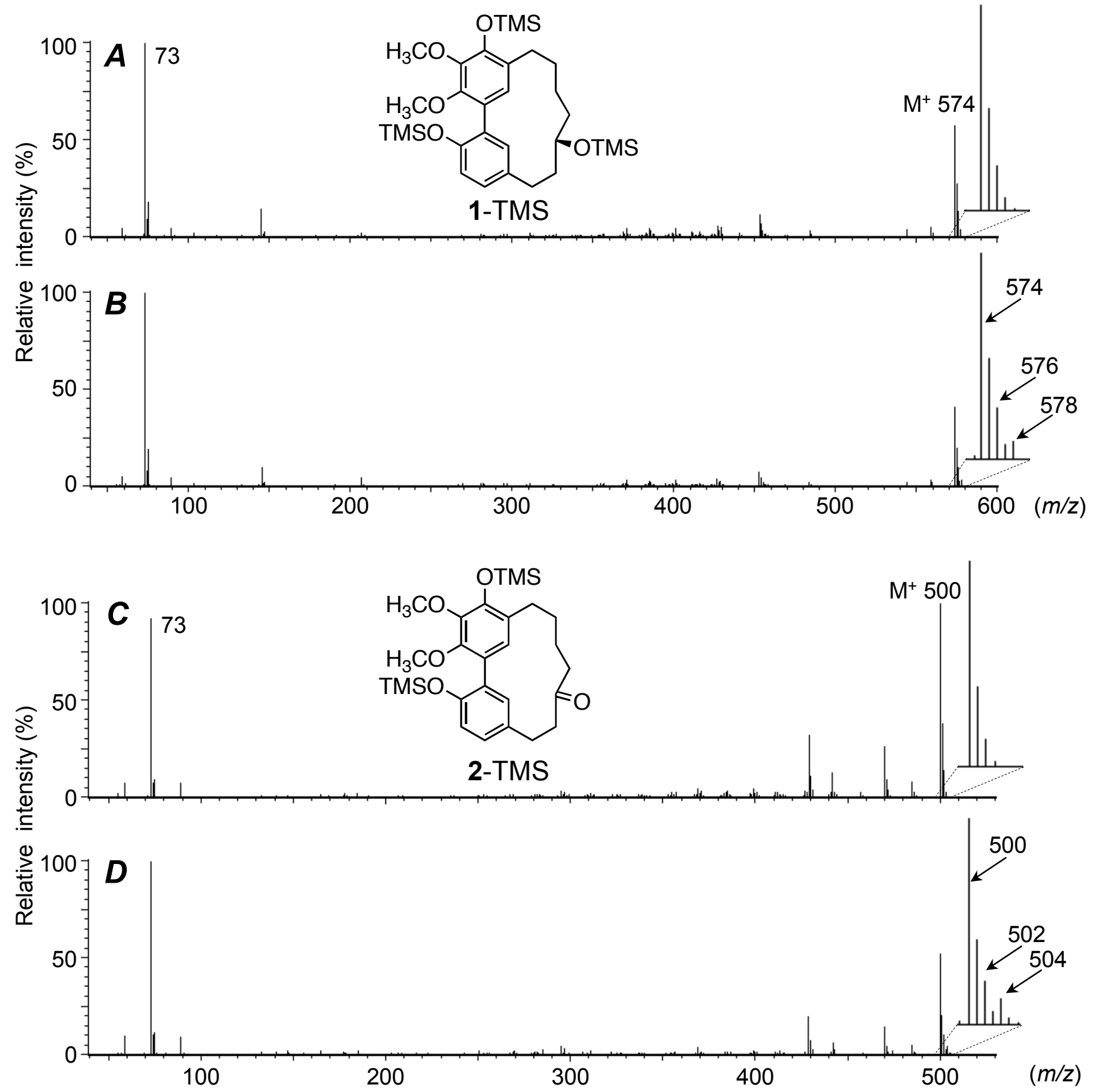


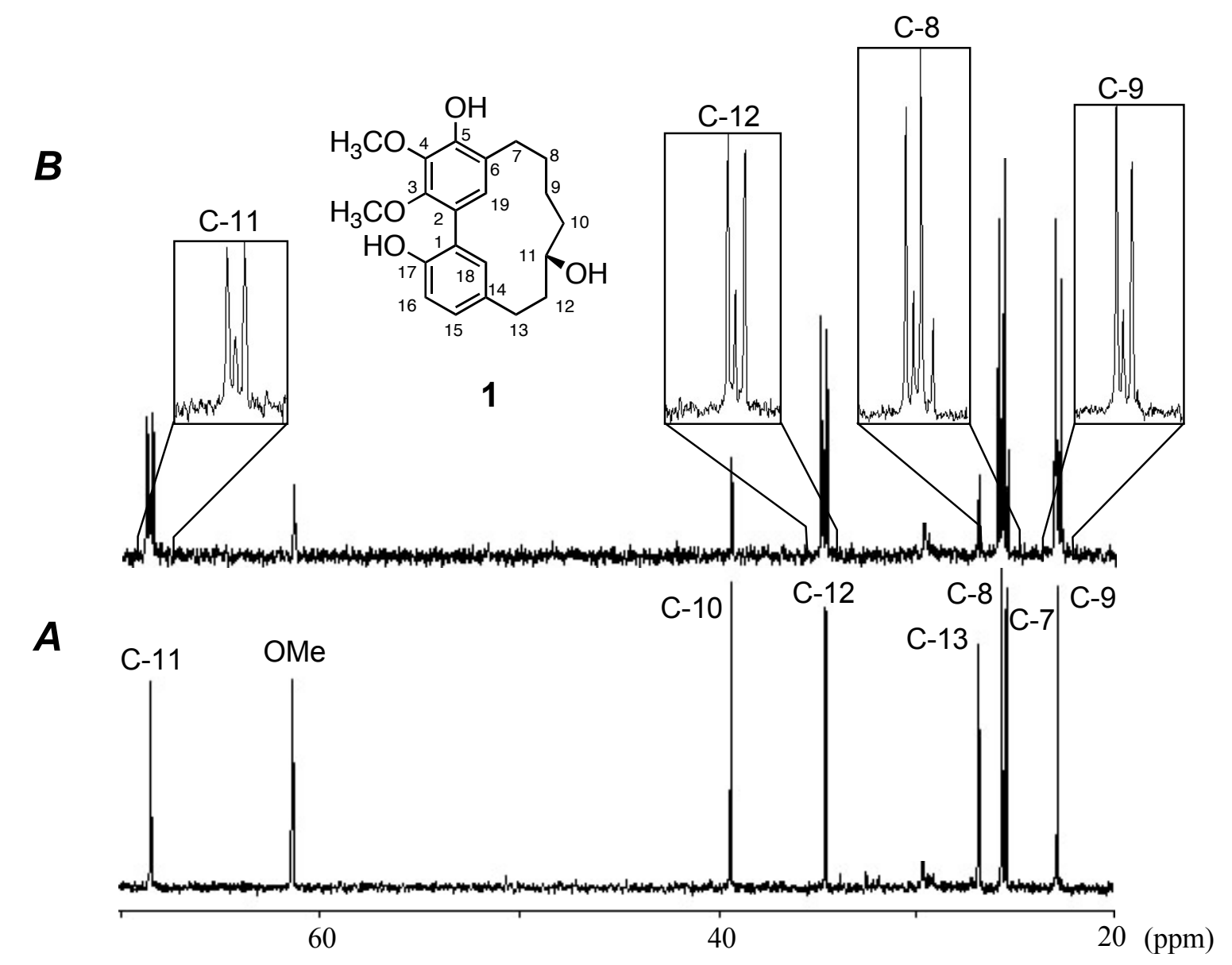




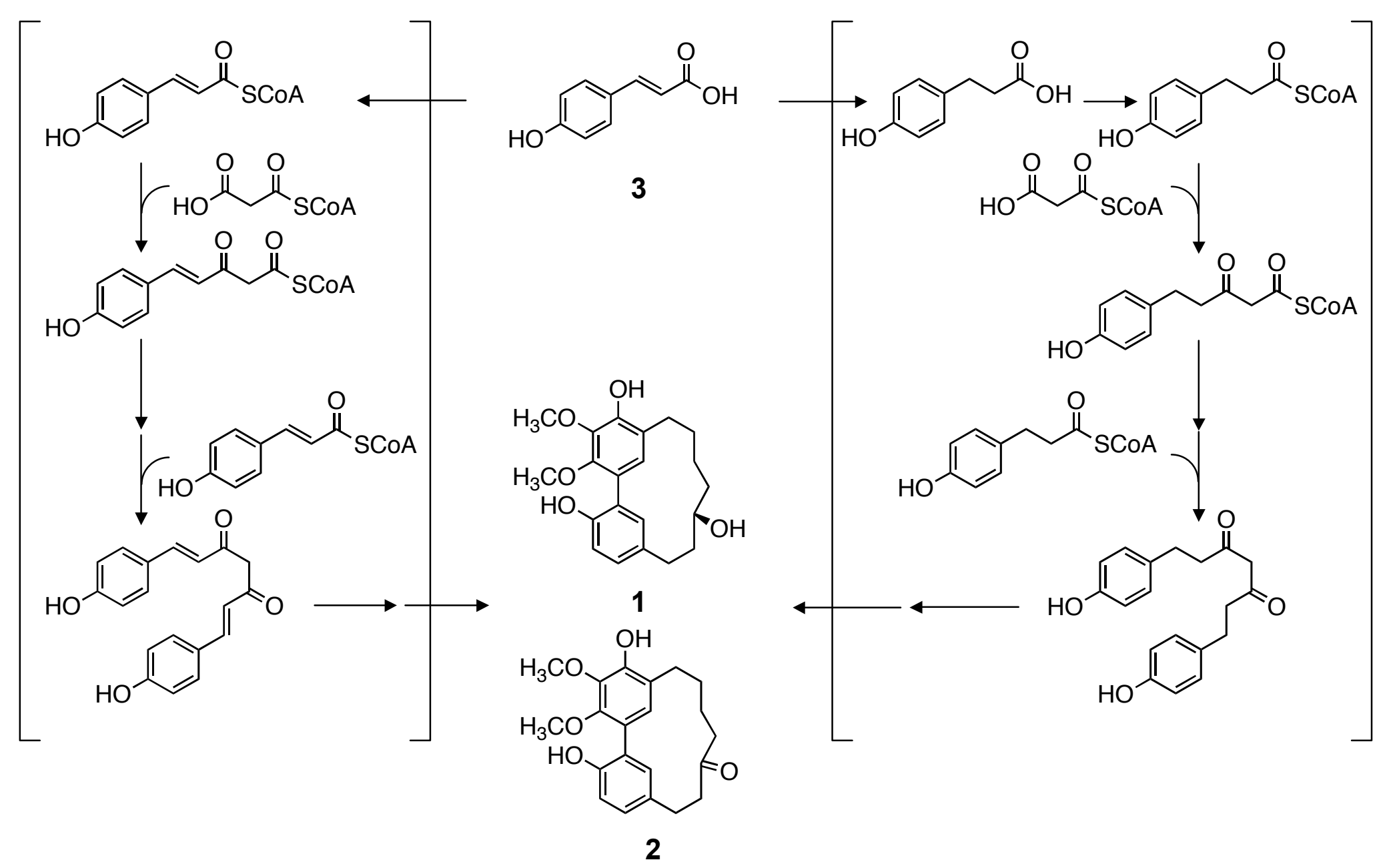

